\title{
O USO DAS TECNOLOGIAS DIGITAIS PARA O ENSINO DE MATEMÁTICA FINANCEIRA: UMA REVISÃO SISTEMÁTICA DE LITERATURA
}

\author{
Claudia Francisco Pelati Teixeira - Programa de Pós-Graduação em Ensino - PPGEN \\ UENP/ Secretaria da Educação do Estado do Paraná - SEED PR - \\ claudiapelatti@gmail.com \\ João Coelho Neto - Programa de Pós-Graduação em Ensino PPGEN UENP - \\ joaocoelho@uenp.edu.br
}

\begin{abstract}
RESUMO
As Tecnologias Digitais da Informação e Comunicação são ferramentas que podem auxiliar no processo de ensino e aprendizagem, principalmente para a área de Matemática, em especial, a Financeira. Desse modo, este artigo visa investigar, por meio de uma Revisão Sistemática de Literatura, de que forma e quais são as tecnologias digitais para o ensino da Matemática Financeira, destacando, o da Planilha Eletrônica que estão sendo utilizadas no contexto escolar. O encaminhamento metodológico utilizado foi o da Revisão Sistemática de Literatura, a pesquisa teve como intervalo de busca os anos de 2006 a 2016, nos seguintes bancos de dados: banco de teses e dissertações da Coordenação de Aperfeiçoamento de Pessoal de Nível Superior e revistas listadas no índice restrito na área de Ensino da plataforma WebQualis. Como resultados, dos 4709 trabalhos analisados, somente 20 tratavam da temática, portanto, os resultados apontam serem poucas as pesquisas que indicam os recursos tecnológicos para o ensino da Matemática Financeira.
\end{abstract}

Palavras-chave: Tecnologia Digitais da Informação e Comunicação; Matemática Financeira; Revisão Sistemática de Literatura; Planilha Eletrônica.

\section{THE USE OF THE DIGITAL TECHNOLOGY FOR THE FINANCIAL MATHEMATICS: A SYSTEMATIC LITERATURE REVIEW}

\begin{abstract}
The Digital Technology of Information and Communication are instruments that it can help the teaching and learning process, mainly for the Mathematics area, in special, the Financial. In this way, the aim of this paper is to investigate, through Systematic Literature Review, how and what are the digital technology for the Financial Mathematics teaching, in particular, the electronic spreadsheet that it is used to the school context. The rearch it was done in the years between 2006 and 2016, in the following databases: in the theses and dissertations platform of the Coordination for the Improvement of Higher Education Personnel (CAPES) and the papers listed in the restricted indice in the Teaching area in the WebQualis platform. As result, the 4709 studies analyzed, only 20 papersapproached the theme of this research, therefore, the results point few researchs that indicate the technology resources for the Financial Mathematic teaching.
\end{abstract}

Keywords: Digital Technology of Information and Communication; Financial Mathematics; Systematic Literature Review; Spreadsheet Electronic.

\section{Introdução}


A inserção do computador como instrumento colaborador no processo de ensino e aprendizagem é consideravelmente recente, em relação a outros meios de tecnologia educacional e tem se mostrado notável facilitador de procedimentos que antes levavam dispendioso tempo para serem executados.

Santos e Giraffa (2010, p.2) apontam que:

[...] atualmente não é suficiente ter conhecimentos básicos acerca do uso do computador, faz-se necessário potencializar este conhecimento na forma de qualificação das relações sociais, da aquisição de conhecimento [...].

De acordo com os Parâmetros Curriculares Nacional de Matemática para o Ensino Médio (BRASIL, 1997), abordam a tecnologia associada a campos diversos da Matemática e suas transformações na criação de novas necessidades e condições de vida, destacando a importância de compreender o desenvolvimento do conhecimento científico e tecnológico, bem como seu papel na vida humana, e seus impactos na vida social.

Desse modo, o uso das mídias, em especial dos softwares de planilhas de cálculo, foco desta pesquisa, podem contribuir com o ensino do conteúdo de Matemática, principalmente o da Financeira, podendo possibilitar uma compreensão mais significativa desse conteúdo.

Conforme Teixeira (2013), um dos motivos para utilizar as Planilhas Eletrônicas para o ensino de Matemática não é apenas o cálculo rápido e preciso, mas a redução do tempo gasto com cálculos repetitivos e já conhecidos.

As operações financeiras fazem parte do cotidiano das pessoas, principalmente em suas práticas de consumo, o poder de compra e parcelamentos que podem comprometer o orçamento das pessoas que enquanto "consumidores" por sua vez, nem sempre foram preparadas pela escola para compreendê-las e, consequentemente, não param para pensar de onde vêm as informações financeiras e como são processadas; simplesmente pagam, sem entender ou por vezes sem questionar.

Diante do exposto, e da importância da temática, o qual trata do uso das Tecnologias Digitais e da Matemática Financeira, percebeu-se a necessidade de organizar uma Revisão Sistemática de Literatura (RSL) dos trabalhos publicados no Banco de Teses e Dissertações da Coordenação de Aperfeiçoamento de Pessoal de Nível Superior (CAPES) e nas revistas qualificadas na área de Ensino. Esta busca teve como intervalo de tempo os anos de 2006 a 2016, buscando quantificar e analisar os trabalhos que tratavam o ensino da Tecnologia e Matemática Financeira, para assim vislumbrar um mapeamento da área, delineando a possibilidade e a viabilidade de trabalhos futuros.

A organização deste artigo se deu em quatro seções: a primeira seção contextualiza o trabalho; a segunda seção, apresenta os materiais e métodos; na terceira, são apresentados os resultados e discussões e, na quarta e última seção, as considerações finais e perspectivas de trabalhos futuros.

\section{Materiais e Métodos}

O método utilizado nesta pesquisa baseou-se na Revisão Sistemática de Literatura de Kitchenham (2004), que entende que uma revisão visa identificar, avaliar e interpretar todas as pesquisas relevantes, a fim de responder um foco de pesquisa específico, sendo que a revisão sistemática é uma forma de estudo secundário.

Para que esta revisão seja executada, algumas etapas definidas por Kitchenham (2004) foram elencadas e adaptadas:

1. Identificação e Planejamento da Pesquisa: as questões de pesquisa elencadas neste trabalho têm como objetivo estruturar ações para a busca e interpretação dos resultados, identificando as seguintes perguntas: Q1: Quais são as Tecnologias Digitais da Informação e Comunicação que estão sendo utilizadas para auxiliar no processo de 
ensino e aprendizagem de Matemática Financeira? Q2: De que forma está sendo usada a Planilha Eletrônica para o ensino da Matemática Financeira? Q3: Qual Planilha Eletrônica está sendo utilizada nos estudos com Matemática Financeira?

Para contemplar as perguntas norteadoras desta pesquisa, os dados a serem pesquisados emergiram das seguintes bases de dados: a primeira pesquisa foi no Banco de Teses e Dissertações da CAPES e a segunda pesquisa visou identificar os periódicos que estão no índice restrito da área de Ensino (A1, A2 e B1). A seleção dos periódicos foi feita por meio do site Periódicos CAPES - Qualis 2014; o período de busca foi de 2005 a abril de 2016; teve como critério de inclusão a leitura dos títulos em que houvesse a palavra "Matemática Financeira", e assim, delinear as pesquisas que apontavam o uso das tecnologias em seu contexto; a busca nas bases de dados foram feitas no período de abril a agosto de 2016, podendo haver alterações, caso a pesquisa seja refeita posteriormente.

2. Seleção de estudos primários: para a seleção dos trabalhos selecionados, seguiram-se as seguintes etapas: seleção dos artigos que apresentavam a palavra-chave "Matemática Financeira". Durante a seleção, verificou-se nos títulos quais continham também a palavra vinculada à temática de tecnologia; assim, procurou-se verificar quais instrumentos estão sendo utilizados; feita esta etapa, realizou-se a leitura dos abstracts; como critério de exclusão, descartaram-se os artigos que não tratavam da temática.

Para um melhor entendimento da etapa 2, segue normativa utilizada para critérios de inclusão: na busca no banco de Teses e Dissertações da CAPES, utilizou-se a palavra "Matemática Financeira" somente e não juntamente com "Tecnologia", visto que o algoritmo de busca retornava um número elevado de trabalhos com esta combinação de palavras. Dessa forma, resolveu-se utilizar o conjunto de palavras "Matemática Financeira", utilizando o critério de exclusão dos trabalhos que não abordavam tecnologia em seu título. Para a busca nas revistas, a leitura deu-se pelo título, seguindo o critério de inclusão, trabalhos que continham as palavras "Matemática Financeira" mais palavras relacionadas com a tecnologia.

3. Estudo da avaliação de qualidade e 4. Extração e monitorização de dados: foi realizada leitura e verificação dos trabalhos selecionados para garantir a pertinência dos trabalhos com a temática pesquisada.

5. Síntese de dados: identificados os trabalhos relevantes, estes são expostos na seção a seguir.

\section{Resultados e Discussão}

Para a primeira pesquisa no site de Dissertações e Teses da CAPES, ao fazer a busca com a palavra-chave "Matemática Financeira", foram retornados 135 trabalhos, dentre os quais fizeram-se as exclusões inicialmente por meio da análise de seus títulos, seguindo-se a leitura dos seus respectivos abstracts para também excluir aqueles que não tratavam do ensino de Matemática Financeira por meio do uso das Tecnologias Digitais da Informação e Comunicação (TDIC). Relacionados ao uso das Planilhas Eletrônicas, restaram 18 trabalhos a serem analisados. Consequentemente, foram excluídas as pesquisas que não consideravam a Matemática Financeira como uma prática de ensino na Educação Matemática, bem como os que não contemplavam as palavras Matemática Financeira, Tecnologias e/ou Planilha Eletrônica.

Dessa forma, a fim de visualizar o panorama dos resultados, elaborou-se a Tabela 1, que mapeia os trabalhos encontrados. 


\begin{tabular}{|c|c|c|c|c|c|}
\hline $\mathbf{N}^{\mathbf{o}}$ & Título do Trabalho de pesquisa - & Autor/Ano & TDIC & $\begin{array}{l}\text { Programa de } \\
\text { Pesquisa }\end{array}$ & $\begin{array}{l}\text { Nota } \\
\text { CA- } \\
\text { PES }\end{array}$ \\
\hline 1. & $\begin{array}{c}\text { Matemática Financeira: um } \\
\text { conhecimento importante para os } \\
\text { estudantes e seu futuro }\end{array}$ & $\begin{array}{l}\text { Henrique M. } \\
\text { Toreate } \\
(2013)\end{array}$ & $\begin{array}{l}\text { Planilha } \\
\text { Eletrônica } \\
\text { Excel }\end{array}$ & $\begin{array}{l}\text { PROFMAT - } \\
\text { UEL }\end{array}$ & 3 \\
\hline 2. & $\begin{array}{c}\text { Matemática Financeira e Planilhas } \\
\text { Eletrônicas: uma abordagem com a } \\
\text { incorporação de recursos } \\
\text { computacionais }\end{array}$ & $\begin{array}{l}\text { Rodrigo Duda } \\
\text { (2014) }\end{array}$ & $\begin{array}{l}\text { Planilhas } \\
\text { Eletrônicas e } \\
\text { Plataforma } \\
\text { Android }\end{array}$ & $\begin{array}{l}\text { PROFMAT - } \\
\text { UEPG }\end{array}$ & 3 \\
\hline 3. & $\begin{array}{l}\text { Matemática Financeira: Uma } \\
\text { aplicação direta no cotidiano }\end{array}$ & \begin{tabular}{|} 
Herbert José \\
Cavalcanti de \\
Souza \\
$(2013)$
\end{tabular} & $\begin{array}{l}\text { Planilhas } \\
\text { Eletrônicas }\end{array}$ & $\begin{array}{l}\text { PROFMAT - } \\
\text { UFPB }\end{array}$ & 4 \\
\hline 4. & $\begin{array}{l}\text { Ensino de Matemática Financeira } \\
\text { com utilização de Tecnologias }\end{array}$ & $\begin{array}{l}\text { Tiago Gadelha } \\
\text { de Sousa } \\
(2014)\end{array}$ & $\begin{array}{l}\text { Calculadoras } \\
\text { simples, } \\
\text { Científica e } \\
\text { Planilha Calc }\end{array}$ & $\begin{array}{l}\text { PROFMAT - } \\
\text { UFCE }\end{array}$ & 6 \\
\hline 5. & $\begin{array}{c}\text { A Matemática Financeira na } \\
\begin{array}{c}\text { Educação Básica e sua importância } \\
\text { para a formação de um cidadão } \\
\text { consciente }\end{array} \\
\end{array}$ & \begin{tabular}{|} 
Priscila Belota \\
de Almeida \\
Ribeiro \\
(2013)
\end{tabular} & Calculadoras & $\begin{array}{l}\text { PROFMAT - } \\
\text { UFRJ }\end{array}$ & 5 \\
\hline 6. & $\begin{array}{l}\text { Um novo olhar para a Matemática } \\
\text { Financeira no ensino médio }\end{array}$ & $\begin{array}{l}\text { Fabio Carlos } \\
\text { Badanai } \\
\text { Tamiao } \\
(2014)\end{array}$ & \begin{tabular}{|c} 
Calculadora \\
Científica, \\
Planilhas \\
Eletrônicas e \\
softwares \\
computacionais
\end{tabular} & $\begin{array}{l}\text { PROFMAT - } \\
\text { UFSCAR }\end{array}$ & 5 \\
\hline 7. & $\begin{array}{l}\text { Matemática Financeira aplicada } \\
\text { aos ensinos }\end{array}$ & $\begin{array}{c}\text { Walquiria } \\
\text { Lemes da } \\
\text { Silveira Faria } \\
(2015)\end{array}$ & \begin{tabular}{|} 
Calculadora e \\
Planilhas \\
Eletrônicas
\end{tabular} & $\begin{array}{l}\text { PROFMAT - } \\
\text { UFGO }\end{array}$ & 4 \\
\hline 8. & $\begin{array}{l}\text { Uso da Planilha Eletrônica excel } \\
\text { como ferramenta didática para o } \\
\text { ensino da Matemática Financeira } \\
\text { no ensino médio }\end{array}$ & $\begin{array}{l}\text { Enilton de } \\
\text { Abreu } \\
\text { Teixeira } \\
(2015)\end{array}$ & $\begin{array}{l}\text { Planilha } \\
\text { Eletrônica } \\
\text { Excel }\end{array}$ & $\begin{array}{l}\text { PROFMAT - } \\
\text { UFTO }\end{array}$ & 3 \\
\hline 9. & $\begin{array}{l}\text { Noções de Matemática Financeira } \\
\text { no ensino médio }\end{array}$ & $\begin{array}{l}\text { Leonardo de } \\
\text { Oliveira } \\
\text { Muniz } \\
\text { (2015) }\end{array}$ & $\begin{array}{c}\text { Software } \\
\text { Geogebra e } \\
\text { Planilha } \\
\text { Eletrônica } \\
\text { Excel }\end{array}$ & $\begin{array}{l}\text { PROFMAT - } \\
\text { UFFlu }\end{array}$ & 3 \\
\hline 10. & $\begin{array}{c}\text { A Matemática Financeira na } \\
\text { educação básica e sua importância } \\
\text { para a formação de um cidadão } \\
\text { consciente }\end{array}$ & $\begin{array}{l}\text { Gisele Valle } \\
\text { de Farias } \\
\text { (2013) }\end{array}$ & Calculadoras & $\begin{array}{l}\text { PROFMAT - } \\
\text { UFRJ }\end{array}$ & 3 \\
\hline 11. & $\begin{array}{c}\text { Construção de calculadoras de } \\
\text { financiamentos usando o Microsoft } \\
\text { Excel: uma proposta de ensino para } \\
\text { a Matemática Financeira }\end{array}$ & $\begin{array}{l}\text { Magnum } \\
\text { Miranda de } \\
\text { Araújo } \\
(2013)\end{array}$ & $\begin{array}{l}\text { Planilha } \\
\text { Eletrônica } \\
\text { Excel }\end{array}$ & $\begin{array}{l}\text { PROFMAT - } \\
\text { UF São } \\
\text { Francisco }\end{array}$ & 3 \\
\hline
\end{tabular}




\begin{tabular}{|c|c|c|c|c|c|}
\hline 12 & $\begin{array}{c}\text { Alunos competentes, consumidores } \\
\text { conscientes: uma proposta para o } \\
\text { ensino da Matemática Financeira } \\
\text { na Educação Básica }\end{array}$ & $\begin{array}{l}\text { Marcia Maria } \\
\text { Azzi Bolotari } \\
\quad(2015)\end{array}$ & $\begin{array}{l}\text { Planilha } \\
\text { Eletrônica } \\
\text { Excel e } \\
\text { calculadora } \\
\text { científica }\end{array}$ & $\begin{array}{l}\text { PROFMAT - } \\
\text { UFJF }\end{array}$ & 3 \\
\hline 13. & $\begin{array}{c}\text { Atividades de Matemática } \\
\text { Financeira na Planilha Eletrônica: } \\
\text { uma aplicação para alunos do } \\
\text { ensino médio }\end{array}$ & $\begin{array}{l}\text { Nilson de } \\
\text { Sousa Santos } \\
\quad(2014)\end{array}$ & $\begin{array}{l}\text { Planilha } \\
\text { Eletrônica } \\
\text { Excel }\end{array}$ & $\begin{array}{l}\text { PROFMAT - } \\
\text { UE Rio Claro }\end{array}$ & 3 \\
\hline 14. & $\begin{array}{c}\text { Atividades Investigativas no } \\
\text { Ensino da Matemática Financeira: } \\
\text { as estratégias empregadas com uso } \\
\text { de Planilhas Eletrônicas }\end{array}$ & $\begin{array}{c}\text { Vinicius } \\
\text { Machacheski } \\
\text { Marchi } \\
\text { (2014) }\end{array}$ & $\begin{array}{l}\text { Planilha } \\
\text { Eletrônica } \\
\text { Excel }\end{array}$ & $\begin{array}{c}\text { PROFMAT - } \\
\text { UNESP }\end{array}$ & 5 \\
\hline 15. & $\begin{array}{c}\text { Atividades Investigativas no } \\
\text { Ensino da Matemática Financeira: } \\
\text { as estratégias empregadas com uso } \\
\text { de Planilhas Eletrônicas }\end{array}$ & $\begin{array}{l}\text { Simone } \\
\text { Regina dos } \\
\text { Reis } \\
(2013)\end{array}$ & $\begin{array}{l}\text { Planilha } \\
\text { Eletrônica } \\
\text { Excel }\end{array}$ & $\begin{array}{l}\text { PROFMAT - } \\
\text { UF Santa } \\
\text { Maria }\end{array}$ & 3 \\
\hline 16. & $\begin{array}{l}\text { A utilização de recursos } \\
\text { computacionais para o ensino da } \\
\text { matemática do ensino médio }\end{array}$ & $\begin{array}{c}\text { Neilton Vieira } \\
\text { da Costa } \\
(2015)\end{array}$ & $\begin{array}{c}\text { Geogebra, } \\
\text { WxMaxima e } \\
\text { Planilha } \\
\text { Eletrônica } \\
\text { Excel }\end{array}$ & $\begin{array}{l}\text { PROFMAT - } \\
\text { UF Triângulo } \\
\quad \text { Mineiro }\end{array}$ & 3 \\
\hline 17. & $\begin{array}{c}\text { Juros compostos, financiamentos e } \\
\text { sistemas de amortização utilizando } \\
\text { a planilha Excel. }\end{array}$ & \begin{tabular}{|} 
Aldo Brasil de \\
Sousa \\
$(2015)$
\end{tabular} & $\begin{array}{l}\text { Planilha } \\
\text { Eletrônica } \\
\text { Excel }\end{array}$ & $\begin{array}{l}\text { PROFMAT - } \\
\text { UFRO }\end{array}$ & 3 \\
\hline 18. & $\begin{array}{l}\text { Educação Matemática Financeira } \\
\text { por meio de sequências didáticas: } \\
\text { duas aplicações cotidianas }\end{array}$ & $\begin{array}{l}\text { Michelle } \\
\text { Ribeiro } \\
\text { Amorim } \\
(2014)\end{array}$ & $\begin{array}{l}\text { Planilha } \\
\text { Eletrônica } \\
\text { Excel }\end{array}$ & $\begin{array}{c}\text { PROFMAT - } \\
\text { UFES }\end{array}$ & 3 \\
\hline
\end{tabular}

Fonte: Os Autores

É possível averiguar na Tabela 1 que, dos 135 trabalhos inicialmente selecionados, destacam-se 18 ou cerca de $13 \%$, que tratam do ensino do conteúdo da Matemática Financeira à luz das tecnologias, aplicadas principalmente por meio das Planilhas Eletrônicas. Na sequência, segue a análise de alguns dos citados anteriormente;

- Araújo (2013) traz uma proposta de ensino voltada ao Ensino Médio em que o uso das calculadoras e da Planilha Eletrônica Excel contribuem para a melhoria do estudo dos conteúdos da Matemática Financeira, consequentemente contribuindo para a educação financeira dos estudantes.

- Farias (2013) considera que a Matemática Financeira é fundamental para o uso cotidiano do cidadão e que a escola por vezes negligencia ou superficializa esse conteúdo e a tecnologia deve ser agregada por se tratar de uma ferramenta facilitadora e agilizadora do processo de ensino desse conteúdo.

- Reis (2013) aponta a necessidade da produção de materiais didáticos que enfatizem situações cotidianas para que a aprendizagem se torne mais significativa, bem como a solução das mesmas por meio das Planilhas Eletrônicas e calculadoras.

- Toraete (2013) expõe em seu trabalho a proposta de uma sequência de atividades a serem resolvidas com auxílio das mídias e tecnologias diversas, que levam o aluno a refletir e resolver situações financeiras, evitando endividamentos. 
- Amorim (2014) traz a proposta da construção, aplicação e validação de duas sequências didáticas para o ensino da Matemática Financeira, com atividades contextualizadas à realidade dos alunos na modalidade de Educação de Jovens e Adultos, abordando a criticidade desses alunos quanto ao uso das tecnologias e cidadania. Foram feitas entrevistas com professores e alunos que associaram as atividades às situações cotidianas, cujos resultados pontuam a satisfação dos estudantes em seus depoimentos, em vista da relação feita por alguns deles com seu trabalho e sua realidade.

- Duda (2014) propõe simuladores eletrônicos como a plataforma Android e a incorporação das Planilhas Eletrônicas, a fim de estimular a manipulação algébrica e as variáveis que compõem as fórmulas financeiras cobradas nas avaliações do Exame Nacional do Ensino Médio e no vestibular da Universidade Estadual de Ponta Grossa. Como resultado final, o autor afirma ser necessário o desenvolvimento de trabalhos futuros voltados ao desenvolvimento de softwares que descrevam modelos algébricos.

- Marchi (2014) propõe investigações filmadas dos alunos realizando atividades de Matemática Financeira no Laboratório de Informática, concluindo que os alunos produziram conceitos sobre acréscimos e descontos, juros, evidenciando que as estratégias promovidas resultaram numa interação do aluno com o software da Planilha Eletrônica Excel, viabilizando o processo de investigação matemática

- Ribeiro (2013) aborda que muitos cursos de Licenciatura em Matemática não contemplam a Matemática Financeira em sua grade curricular e propõe o ensino da Matemática Financeira com atividades do cotidiano do aluno, contando com a tecnologia das calculadoras como ferramenta facilitadora e enriquecedora das aulas.

- Santos (2014), por sua vez, se preocupa com atividades e exercícios de Matemática Financeira que podem ser desenvolvidos e realizados no laboratório de informática das escolas e como resultado demonstra o quanto os modos tradicionais de cálculo são inviáveis frente às ferramentas tecnológicas disponíveis, a exemplo das Planilhas Eletrônicas.

- Souza (2014) faz uso da ferramenta eletrônica planilhas de cálculo para auxiliar a resolver cálculos financeiros extensos em eventos ligados à nossa realidade. $\mathrm{O}$ efeito dessa ação está em o leitor financeiro responder as questões que envolvem escolhas financeiras, bem como calcular os componentes de um financiamento e construir tabelas de amortizações.

- Souza (2013) trata de como é a vida do cidadão, seus sonhos de consumo e motivações, utiliza calculadoras e Planilhas Eletrônicas de cálculo e fala sobre a pouca atenção que se dá ao ensino da Matemática Financeira.

- Tamião (2014) visa à aprendizagem significativa da Matemática Financeira no Ensino Médio por meio da idealização e aplicação de uma sequência didática com problemas contextualizados que se utilizam de calculadoras e Planilhas Eletrônicas. Conclui que é um trabalho satisfatório com pouca intervenção do professor, percebendo a superação das dificuldades, uma vez que a aprendizagem dos alunos vai além das percepções do professor.

Em síntese, é notório que os trabalhos analisados compartilham da mesma preocupação com o ensino da Matemática Financeira, em especial na Educação Básica, dado que, em conformidade aos Parâmetros Curriculares Nacionais (BRASIL, 1998, p. 60), o ensino da Matemática deve proporcionar ao aluno "[...] compreender a realidade em que está inserido, desenvolva suas capacidades cognitivas e sua confiança para enfrentar desafios [...]”.

Dessa forma, é perceptível o quanto as TDIC, em especial as Planilhas Eletrônicas para o ensino da Matemática Financeira, apresentam um cenário propício a pesquisas que possibilitam estabelecer relações coerentes com a prática financeira social e, na busca de 
reunir um número maior de trabalhos que possam salientar a eficácia do uso dessas tecnologias como metodologia de ensino, estendeu-se a revisão sistemática a revistas qualificadas na área de Ensino.

Para a segunda pesquisa, o estudo faz um mapeamento das produções científicas publicadas em algumas das principais revistas/periódicos qualificados como A1, A2 e B1 na plataforma WebQualis ano 2014, na área de Ensino, abrangendo o intervalo de busca os últimos dez anos; a busca foi feita nos meses de abril a agosto de 2016.

Foi realizada a análise somente em revistas de língua portuguesa, as quais foram elencadas, ocorrendo a seleção conforme a concentração voltada à Tecnologias e Educação Matemática.

Por conseguinte, uma leitura e análise visual detalhada dos títulos dos artigos (um a um) listados no sumário das publicações das revistas na última década desencadearam o processo de exclusão, no intuito de isentar os trabalhos que não tratavam do Ensino da Matemática Financeira à luz das tecnologias (Planilha Eletrônica) e, concomitantemente, identificar e resgatar trabalhos que abordavam a temática para posterior leitura e análise.

Foi dada atenção especial ao resumo quando no título não estava bem claro o emprego das tecnologias, principalmente, as Planilhas Eletrônicas para o trato da Matemática Financeira, sendo também eliminados da análise aqueles que não fizeram uso de algum recurso tecnológico, principalmente dos softwares de cálculo das Planilhas Eletrônicas.

A Tabela 2 traz uma síntese dos resultados da pesquisa realizada em algumas das principais revistas e periódicos da plataforma WebQualis nos últimos dez anos, que tratam o ensino da Matemática Financeira por meio de Planilhas Eletrônicas de cálculo.

Tabela 2 - Mapeamento dos Artigos nas Revistas

\begin{tabular}{|c|c|c|c|c|c|}
\hline $\begin{array}{l}\text { Revista/ } \\
\text { Periódico }\end{array}$ & Qualis & ISSN & $\begin{array}{c}\text { Período do } \\
\text { levantamento }\end{array}$ & $\begin{array}{c}\text { Total de } \\
\text { artigos } \\
\text { pesquisados }\end{array}$ & $\begin{array}{c}\text { Total de } \\
\text { artigos que } \\
\text { abordavam } \\
\text { a temática }\end{array}$ \\
\hline BOLEMA & A1 & $0103-636 X$ & $2006-2015$ & 610 & 1 \\
\hline $\begin{array}{l}\text { Ciência e } \\
\text { educação }\end{array}$ & A1 & $1980-850 X$ & $2006-2015$ & 504 & 0 \\
\hline $\begin{array}{c}\text { Educação e } \\
\text { Realidade }\end{array}$ & A2 & $2175-6236$ & $2006-2015$ & 463 & 0 \\
\hline Ensaio & A 2 & $1983-2117$ & 2006-2015 & 251 & 0 \\
\hline $\begin{array}{c}\text { Educação em } \\
\text { Revista }\end{array}$ & A 2 & $1982-6621$ & $2006-2015$ & 465 & 0 \\
\hline $\begin{array}{l}\text { Educere et } \\
\text { Educare }\end{array}$ & B1 & $1981-4712$ & $2006-2015$ & 461 & 0 \\
\hline REVEMAT & $\mathrm{B} 1$ & 1981-1322 & 2006-2015 & 182 & 1 \\
\hline Alexandria & B1 & $1982-5153$ & $2008-2015$ & 220 & 0 \\
\hline $\begin{array}{c}\text { Educação } \\
\text { Matemática } \\
\text { em Revista }\end{array}$ & B1 & $1518-8221$ & $2006-2015$ & 113 & 0 \\
\hline RENOTE & B1 & 1679-1916 & 2006-2015 & 1126 & 0 \\
\hline Zetetiké & B1 & $2176-1744$ & $2006-2015$ & 179 & 0 \\
\hline \multicolumn{4}{|c|}{ Total geral de artigos pesquisados e selecionados } & 4574 & 2 \\
\hline
\end{tabular}

Fonte: Os autores 
A Tabela 2 apresenta os resultados da pesquisa por artigos publicados em 12 revistas/periódicos na área de Ensino dentre os anos de 2006 a 2016, classificados no portal Webqualis como A1, A2 e B1, no Qualis 2014, dos 4574 artigos encontrados, e que após análise, 2 (dois) desses trataram do ensino da Matemática Financeira à luz das tecnologias, revelando o baixo número de publicações com a temática.

Sobre os artigos encontrados, segue uma breve análise:

\begin{tabular}{|c|c|l|c|}
\multicolumn{4}{|c|}{ Quadro 1 - Artigo BOLEMA } \\
\hline Revista & Vol./Num./Ano & \multicolumn{1}{|c|}{ Autor(es) } & \multicolumn{1}{c|}{ Título } \\
\hline BOLEMA & $19 / 26 / 2006$ & $\begin{array}{l}\text { GOUVEIA A. S. } \\
\text { SIMONE }\end{array}$ & $\begin{array}{c}\text { Novos Caminhos para o Ensino e } \\
\text { Aprendizagem de Matemática } \\
\text { Financeira: construção e aplicação } \\
\text { de WebQuest }\end{array}$ \\
\hline
\end{tabular}

Fonte: Os autores

$\mathrm{O}$ artigo "Novos Caminhos para o Ensino e Aprendizagem de Matemática Financeira: construção e aplicação de Web Quest", considera a criação de WebQuests para o ensino da Matemática Financeira como tecnologia empregada na criação de um ambiente construcionista vindo a investigar e contribuir na formação inicial docente e na prática pedagógica dos licenciandos em Matemática considerando ainda a importância da Educação Financeira na vida das pessoas, porém, como ferramenta foco desta pesquisa, não houve o uso de Planilhas Eletrônicas.

A seguir, identifica-se na pesquisa da Revista REVEMAT, a presença um artigo com a temática;

Quadro 2 - Artigo REVEMAT

\begin{tabular}{|c|c|l|c|}
\hline Revista & Vol./Num./Ano & \multicolumn{1}{|c|}{ Autor (es) } & Título \\
\hline \multirow{2}{*}{ REVEMAT } & $07 / 02 / 2012$ & $\begin{array}{l}\text { ROSETTI J. H.; } \\
\text { SCHIMIGUEL, J. } \\
(2012)\end{array}$ & $\begin{array}{c}\text { Estudo das percepções de } \\
\text { alunos dos cursos } \\
\text { tecnológicos sobre os } \\
\end{array}$ \\
& & modelos financeiros usuais \\
\hline
\end{tabular}

Fonte: Os autores

Rosseti Junior e Schimiguel (2012) discutem os modelos financeiros e fazem uma reflexão sobre a importância da aplicação dos conhecimentos tecnológicos, mostrando o quanto os alunos têm dificuldade em lidar com os conceitos elementares das finanças e o quanto a tecnologia das Planilhas Eletrônicas como o Excel e calculadoras científicas viabilizam esse processo.

Em termos quantitativos, este resultado levou em conta a distribuição dos trabalhos em características quanto ao título, palavras-chave e resumo, analisando 4.574 artigos, dos quais apenas 2, ou seja, 0,04\% (menos de meio por cento) abordam a temática do ensino da Matemática Financeira por meio das tecnologias. Nota-se ainda que os artigos encontrados fragmentam a temática e não tratam do assunto por completo, ora abordam a Matemática Financeira ora abordam a Tecnologia, sendo notoriamente raro a junção dos dois assuntos.

Devido ao expressivo número de artigos publicados nos periódicos mencionados na Tabela 2, há de se considerar a quão ínfima é a quantidade de trabalhos que abordam o tema da análise. Cabe, assim, a motivação do estudo da temática no que se refere ao ensino e, como consequência, à aprendizagem, com o desenvolvimento de ações que permitam engajamento no ensino da Matemática Financeira utilizando-se a tecnologia por meio das Planilhas Eletrônicas, a fim de propiciar aos estudantes conhecimento para o seu desenvolvimento frente às situações financeiras.

\section{Considerações Finais}

V. $14 \mathrm{~N}^{\mathrm{o}} 2$, dezembro, 2016 
Com esse trabalho de revisão sistemática, foi possível apontar a carência de trabalhos elaborados na última década, de 2006 a 2016, em relação à demanda que rege o ensino dos conteúdos de Matemática Financeira na Educação Básica, por meio das tecnologias, em especial, das Planilhas Eletrônicas.

Dentre as informações citadas nas tabelas, emergem conhecimentos que buscam responder a Q1: Quais são as Tecnologias Digitais da Informação e Comunicação que estão sendo utilizadas para auxiliar no processo de ensino e aprendizagem de Matemática Financeira? Após análise dos trabalhos, é perceptível que entre tantos instrumentos tecnológicos, os que foram mais abordados são as Planilhas Eletrônicas Excel, que, em cerca de 55\% dos trabalhos, aparecem como único recurso, seguidos de cerca de $33 \%$ que exploram mais de um recurso no mesmo trabalho, como calculadoras e outros softwares e aproximadamente $11 \%$ fazem uso exclusivo de calculadoras.

Atendendo a argumentação da Q2: De que forma está sendo trabalhada a Planilha Eletrônica para o ensino da Matemática Financeira? Há que se considerar o fato de que os trabalhos analisados comungam da ideia de não mais ensinar por meio de situações abstratas em problemas que abordam contextos que fogem das possibilidades e da realidade de vida do aluno. Dessa forma, procura-se aplicar ao conteúdo situações reais com exercícios que proporcionem o crescimento do aluno enquanto cidadão, de maneira que agregar a utilização das tecnologias, principalmente as Planilhas Eletrônicas de cálculo é um fator favorável e indiscutível, pois isso pode atender às necessidades da sociedade e do mercado de trabalho.

A busca revelou que as Planilhas Eletrônicas são um instrumento pouco explorado para o ensino da Matemática Financeira e, com os resultados encontrados nessa pesquisa, os dados inferem para a resposta à terceira questão, Q3: Qual Planilha Eletrônica está sendo utilizada nos estudos com Matemática Financeira? Apesar da Planilha Eletrônica Calc ser um software disponibilizado gratuitamente, é a Planilha Eletrônica Excel a mais recorrente nos trabalhos de pesquisa, sendo notório ainda que os trabalhos de pesquisas trazem os procedimentos detalhados em como "lidar" com essas planilhas para resolver as atividades propostas.

Em suma, o estudo desenvolvido por essa revisão sistemática fez um levantamento dos trabalhos que vêm sendo desenvolvidos acerca do ensino da Matemática Financeira à luz da tecnologia por meio das Planilhas Eletrônicas, cabendo a consideração sobre a não saturação desse assunto e, por assim dizer, dando margem a intenções de desenvolvimento de trabalhos futuros.

Dessa forma, para encaminhamentos futuros, tenciona-se desenvolver uma sequência didática a fim de auxiliar no conteúdo da Matemática Financeira à luz da utilização do software Calc na tentativa de auxiliar no processo de ensino e de aprendizagem, principalmente para as escolas públicas, pois o software Calc é gratuito, podendo ser utilizado em todos os níveis e sistemas de ensino.

\section{Referências}

AMORIN, M. R. Educação Matemática Financeira por meio de sequências didáticas: duas aplicações cotidianas. UF Espírito Santo, 2014. Dissertação de Mestrado.

ARAÚJO, M. M. Construção de calculadoras de financiamentos usando o Microsoft Excel: uma proposta de ensino para a Matemática Financeira. UF São Francisco, 2013. Dissertação de Mestrado.

BRASIL. Ministério da Educação. Secretaria de Educação Básica: Parâmetros Curriculares Nacionais de Matemática. Brasília -DF. 1998. 
CAPES. Banco de Teses e Dissertações Tabela de áreas do conhecimento. 2014. Disponível em http://bancodeteses.capes.gov.br/banco-teses. Acesso em 01 ago. 2016.

DUDA, R. Matemática Financeira e Planilhas Eletrônicas: uma abordagem com a incorporação de recursos computacionais. UEPG, 2014. Dissertação de Mestrado.

FARIAS, G. V. A Matemática Financeira na educação básica e sua importância para a formação de um cidadão consciente. UFRJ, 2013. Dissertação de Mestrado.

GOUVEIA A. S. S. Novos Caminhos para o Ensino e Aprendizagem de Matemática Financeira: construção e aplicação de WebQuest. BOLEMA, Boletim de Educação Matemática, Rio Claro, SP v. 19, n. 26, p. 2006

KITCHENHAM, B. A. Procedures for Performing Systematic Reviews. Tech. Report TR/SE-0401, Keele University, 2014.

MARCHI, V. M. Atividades Investigativas no Ensino da Matemática Financeira: as estratégias empregadas com uso de Planilhas Eletrônicas. UNESP, 2014. Dissertação de Mestrado.

MARTINS, F.; GONÇALVES O. Informática na Educação Matemática e Científica dos anos iniciais de escolaridade: um estudo sobre as pesquisas da área de ensino de Ciências e Matemática. Ensaio Pesquisa em Educação em Ciências. Belo Horizonte, vol.14, n.3, 2014.

REIS, S. R. Atividades Investigativas no Ensino da Matemática Financeira: as estratégias empregadas com uso de Planilhas Eletrônicas. UF Santa Maria, 2013. Dissertação de Mestrado.

RIBEIRO, P. B. A Matemática Financeira na Educação Básica e sua importância para a formação de um cidadão consciente. UFRJ, 2013. Dissertação de Mestrado.

ROSETTI J.; SCHIMIGUEL, J.; Estudo das percepções de alunos dos cursos tecnológicos sobre modelos financeiros usuais. REVEMAT: Revista Eletrônica de Educação Matemática, Florianópolis, v. 7, n. 2, p. 90-103, dez. 2012.

SANTOS, K.; GIRAFFA, M.; Capacitação de professores a distância e Inclusão Digital: a integração possível. RENOTE: Revista Novas Tecnologias na Educação, PUC-RS, v. 08, n. 01, 2010.

SOUSA, T. Ensino de matemática financeira com utilização de tecnologias. UFCE, 2014. Dissertação de Mestrado.

SOUZA, A. B. Juros compostos, financiamentos e sistemas de amortização utilizando a planilha Excel. UFRO, 2015. Dissertação de Mestrado.

TAMIÃO, F. C. Um novo olhar para a Matemática Financeira no ensino médio. UFSCAR, 2014. Dissertação de Mestrado.

TEIXEIRA, E.; Uso da Planilha Eletrônica Excel como ferramenta didática para o ensino da Matemática Financeira no ensino médio. 2015. Dissertação de Mestrado.

TOREATE, H.; Matemática Financeira: um conhecimento importante para os estudantes e seu futuro. 2013. Dissertação de Mestrado. 